\title{
A VIVÊNCIA DE ADOLESCENTES ASSISTIDAS POR ENFERMEIROS OBSTETRAS DURANTE O PROCESSO DE PARTURIÇÃO
}

\section{THE EXPERIENCE OF ADOLESCENTS ASSISTED BY OBSTETRIC NURSES DURING PARTURITION}

\section{LA EXPERIENCIA DE ADOLESCENTES ASISTIDAS POR ENFERMEROS OBSTÉTRICOS DURANTE EL PROCESO DE PARTO}

Priscilla Cavalcante Lima ${ }^{1}$, Milena France Alves Cavalcante ${ }^{2}$, Simone Silva e Santos Melo ${ }^{2}$, Verbênia Cipriano Feitosa ${ }^{2}$, Márcia Teles de Oliveira Gouveia ${ }^{3}$

\section{RESUMO}

Objetivos: descrever a vivência de adolescentes durante o processo de parturição e a atuação da enfermagem obstétrica com base nos depoimentos das adolescentes e discutir à luz da literatura pertinente. Método: pesquisa descritiva, exploratória, de natureza qualitativa, com dez puérperas adolescentes do alojamento conjunto da Maternidade de Referência Estadual do Piauí, mediante entrevista semiestruturada analisada com os preceitos da análise temática. Resultados: permitiu identificar o aflorar de sentimentos e sensações das adolescentes no processo parturitivo como a dor e a satisfação de ver o filho e a inserção de tecnologias não invasivas de alívio da dor utilizadas pelos enfermeiros obstetras. Conclusão: As adolescentes reconheceram os benefícios das tecnologias não invasivas de alívio da dor para a redução do tempo do trabalho de parto e a importância da atuação do enfermeiro obstetra.

Descritores: Enfermagem obstétrica; Parto humanizado; Adolescente.

\section{ABSTRACT:}

Objectives: To describe the experience of adolescents in the process of parturition and the performance of obstetrical nursing based on the testimonies of adolescents and discussing in the light of the relevant literature. Method: descriptive, exploratory, qualitative study, with ten teenage mothers from the rooming at State Reference Maternity of Piauí, through semi-structured interviews analyzed with the principles of thematic analysis. Results: it was identified the flourishing of feelings and sensations of teenagers in the birth process as pain and pleased to see the child and the inclusion of non-invasive technologies of pain relief used by midwives. Conclusion: Adolescents recognized the benefits of non-invasive technologies of pain relief for reduction of labor time and the importance of the role of the obstetrician nurse.

Descriptors: Obstetrical nursing; Humanizing Delivery; Adolescent.

\section{RESUMEN:}

Objetivos: Describir la experiencia de los adolescentes en el proceso de parto y el rendimiento de enfermería obstétrica en base a los testimonios de los adolescentes y discuten a la luz de la literatura relevante. Metodo: Estudio descriptivo, exploratorio, cualitativo, con diez madres adolescentes desde el alojamiento conjunto de maternidad Estado de Piauí de referencia, a través de entrevistas semiestructuradas analizadas con los principios del análisis temático. Resultados: identifican el florecimiento de sentimientos y sensaciones de los adolescentes en el proceso de nacimiento como el dolor y el placer de ver al niño y la inclusión de tecnologías de alivio del dolor no invasivo utilizado por una comadrona. Conclusión: Los adolescentes reconocen los beneficios de las tecnologías no invasivas de alivio del dolor para la reducción del tiempo de trabajo y la importancia del papel de la enfermera obstetra.

Descriptores: Enfermería obstétrica; Parto humanizado; Adolescente.

${ }^{1}$ Graduada em Enfermagem. Mestranda em Enfermagem pela Universidade Federal do Piauí. ${ }^{2}$ Graduada em Enfermagem. Mestre em Enfermagem pela Universidade Federal do Piauí. ${ }^{3}$ Graduada em Enfermagem e licenciatura. Doutora em Ciências pela Escola de Enfermagem de Ribeirão Preto da Universidade de São Paulo. 


\section{INTRODUÇÃO}

A adolescência é a transição entre a infância e a fase adulta, nessa etapa da vida acontecem diversas modificações no desenvolvimento biopsicossocial, no qual muitas vezes também ocorre o início da vida sexual. A Organização Mundial da Saúde (OMS) circunscreve a adolescência à segunda década da vida (de 10 a 19 anos).

Nessa fase ocorrem descobertas, inquietações, formação de atitudes, valores e comportamentos, que exigem intervenções das equipes de saúde com uma abordagem integral do cuidado ${ }^{(1,2)}$.

$\mathrm{Na}$ adolescência, os jovens sentem-se excitados a vivenciar situações diferentes, sobretudo em relação à sexualidade, e estes atos impulsivos podem levar a uma gravidez inesperada. A gestação representa grandes mudanças físicas, sociais e emocionais para qualquer mulher, porém essas transformações apresentam maior impacto nas adolescentes, devido os aspectos biológicos e emocionais inerentes à adolescência, além disso, frequentemente a gravidez não é planejada, enfrentam instabilidade nas relações familiares e conjugais, assim a gravidez na adolescência é preocupante devido as implicações orgânicas e sociais $^{(3)}$.

As inúmeras transformações em relação à assistência ao parto acontecem continuadamente. No início do século $X X$, o parto era quase exclusivamente normal e domiciliar, já nas décadas de 1930 e 1960, existiam simultaneamente os modelos de assistência ao parto hospitalar e domiciliar, assistidos por parteiras ou médicos. A partir da década de 70 o parto passou a ser exclusivamente hospitalar assistido por médicos ${ }^{(4)}$. Na década de 90 , as críticas ao modelo biomédico obstétrico intensificaram-se, devido ao desrespeito do direito de escolha das mulheres sobre seu tipo de parto e as práticas obstétricas intervencionistas ${ }^{(5)}$.

$\mathrm{Na}$ tentativa de resgate do caráter fisiológico do nascimento, em 2000 o Ministério de Saúde implantou o Programa de Humanização do Pré-Natal e Nascimento (PHPN), para a humanização da assistência obstétrica.

A humanização da assistência tem contribuindo para o protagonismo da mulher e para compreensão do vínculo entre cultura e natureza humana no processo de gestação, parto e nascimento tornando o processo parturitivo um momento natural, pois essa assistência visa reduzir as intervenções para o favorecimento dos processos fisiológicos envolvidos no nascimento, com respeito a individualidade, promovendo o acolhimento e vínculo mãe-bebê( ${ }^{(6,7)}$.

Dando continuidade ás estratégias para a humanização do parto e nascimento, foi lançada em 2011 a Rede Cegonha, que é uma estratégia do Ministério da Saúde que tem como objetivo implementar uma rede de cuidados que garantam às mulheres o direito ao planejamento reprodutivo, atenção humanizada à gravidez, ao parto e ao puerpério e às crianças o direito ao nascimento seguro e ao crescimento e ao desenvolvimento saudáveis. Além disso, incentiva a ampliação dos Centros de Parto Normal, nos quais o enfermeiro obstetra coordena a assistência, promovendo o protagonismo da mulher, favorecendo o parto como um evento natural e familiar ${ }^{(8)}$.

Entretanto em maternidades que ainda não se adequaram totalmente aos princípios da Rede cegonha, a mulher perde sua privacidade e autonomia no trabalho de parto e parto é submetida a normas institucionais e práticas intervencionistas. A inserção dos enfermeiros obstetras na equipe multiprofissional no cenário de humanização do processo de parturição é essencial, pois a formação desse profissional é pautada no cuidado e na valorização dos aspectos fisiológicos do parto, valoriza e considera os direitos da mulher, promovendo o vínculo entre profissional e paciente, podendo assim, evitar as intervenções desnecessárias e contribuir para a redução dos índices de mortalidade materna ${ }^{(6)}$.

O presente estudo partiu do interesse pela temática despertado durante as práticas do curso de residência de enfermagem obstétrica da Universidade Federal do Piauí desenvolvidos em uma maternidade de referência estadual do Piauí, pois no mesmo há um grande índice de partos de adolescentes, assim como a expansão da atuação dos enfermeiros obstetras. $E$ entender o que as adolescentes vivenciam durante 0 processo parturitivo é essencial para que ocorram mudanças na assistência e na postura profissional para atender esse público, diante disso, o estudo teve como objetivo descrever a vivência de adolescentes durante o processo de parturição e a atuação da enfermagem obstétrica nesse processo, com base nos seus depoimentos e discutir à luz da literatura pertinente. 


\section{MÉTODO}

Trata-se de estudo descritivo-exploratório com abordagem qualitativa realizada no alojamento conjunto da Maternidade de Referência Estadual do Piauí, localizado na cidade de Teresina.

A coleta de dados deu-se durante os meses de maio e junho de 2015, após a autorização e aprovação do Comitê de Ética em Pesquisa da Universidade Federal do Piauí, conforme também prevê a Resolução no 466/12 do Conselho Nacional de Saúde (CNS) tendo sido aprovado sob o protocolo CAAE 42322815.3.0000.5214. Os responsáveis pelas adolescentes assinaram o Termo de Consentimento Livre e Esclarecido (TCLE) condicionando a sua participação, e assegurando o anonimato e o sigilo das informações, assim como o termo de Assentimento que foi assinado pelas menores de 18 anos $^{(9)}$.

As participantes da pesquisa foram dez puérperas adolescentes do referido alojamento conjunto que atenderam aos seguintes critérios de inclusão: 1) puérperas em idades entre 15-19 anos, pois as enfermeiras obstetras estão habilitadas para assistir parturientes de baixo risco, que no tocante a faixa etária são aquelas compreendidas entre 15 e 35 anos. E a OMS considera adolescentes os indivíduos que estão na faixa etária entre 10 e 19 anos; 2) parto de baixo risco, sem nenhuma alteração patológica; 3) processo de parturição assistido por enfermeiros obstetras que evoluiu para parto normal $^{(2,10)}$.

As puérperas adolescentes foram convidadas a participar do estudo pela pesquisadora, enquanto as mesmas estavam internadas nas enfermarias de alojamento conjunto da maternidade referida anteriormente. Os dados foram coletados por meio de entrevista semiestruturada, que ocorreu na enfermaria onde encontravam- se as participantes, aquela possui divisórias entre os leitos, o que permitiu que as entrevistas fossem realizadas com privacidade e sem a presença do acompanhante no momento das entrevistas.

Utilizou o critério de saturação, ou seja, quando as falas começaram a se repetir para o encerramento da coleta de dados. Para o tratamento das informações coletadas, utilizou-se a análise temática ${ }^{(11)}$. Sendo assim, as categorias encontradas e que serão discutidas foram: vivências das adolescentes durante o processo de parturição: o aflorar de sentimentos e sensações e a assistência do enfermeiro obstetra segundo o olhar das parturientes assistidas. As entrevistadas foram identificadas como " $A$ " de adolescente e receberam um código numérico sequencial de 01 a 10 para assegurar o sigilo e o anonimato do respectivo depoimento.

\section{RESULTADOS E DISCUSSÃO}

Em relação à escolaridade das participantes, 1 das adolescentes tinha ensino fundamental incompleto, 2 tinham ensino fundamental completo, 4 tinham ensino médio incompleto e 3 possuíam ensino médio completo. Demonstrando que a maioria das adolescentes entrevistadas possuía mais de 07 anos de estudo, mas nenhuma havia iniciado o ensino superior.

$E$, quanto ao estado civil, 04 eram solteiras, 03 eram casadas e 03 viviam em união estável. Em relação ao número de gestações, foi identificado que as 10 entrevistadas estavam na sua primeira gestação. Isso torna a adolescente mais vulnerável, pois as mudanças comuns da adolescência são associadas as alterações causadas pela gestação, aumentando assim os medos e anseios das mesmas ${ }^{(12)}$.

$\mathrm{Em}$ relação à situação financeira, 7 possuíam uma renda de um salário mínimo e 3 possuíam menos de um salário mínimo como renda; no que se refere à naturalidade, 5 eram naturais de Teresina, capital do Piauí, 1 de São Pedro do Piauí, 2 eram de Barras, essas são cidades do interior do Piauí e 2 eram naturais de Brasília, capital do Distrito Federal.

Quanto ao número de consultas do prénatal, observou-se que todas o fizeram, ocorrendo variação entre 2 e 10 consultas, sendo que 7 realizaram entre 6 e 10 consultas, o que é preconizado pelo Ministério da Saúde de que todas as gestantes devem realizar no mínimo 6 consultas de pré-natal ${ }^{(12)}$. As outras 3 realizaram entre 2 e 5 consultas.

\section{Vivências das adolescentes durante o processo de parturição: o aflorar de sentimentos e sensações}

O significado da gravidez na adolescência varia de acordo com o contexto e o tempo histórico em que é vivenciada, muitas vezes a experiência das adolescentes durante o parto é crítica, principalmente pela sensação de dor intensa, é um período de vulnerabilidade, e o parto nesse momento da vida é marcado por mudanças significativas, físicas e emocionais e que envolvem os medos relacionados a esse momento ${ }^{(12)}$. 
A primeira categoria para análise das informações coletadas diz respeito ao aflorar de sentimentos e sensações vivenciados pelas adolescentes no processo de parturição. A sensação é entendida ora como fenômeno fisiológico, ora como correspondência psíquica às excitações físicas, é um acontecimento intensivo, incomunicáveis, intransmissíveis, que não têm significado, e sim a realidade. Já o sentimento é um estado vivido acarretado à percepção de um tempo fenomenológico ${ }^{(13)}$.

Durante as entrevistas, observaram-se várias demonstrações verbais e não verbais de como essas adolescentes vivenciaram a experiência do processo parturitivo, cheio de novidades e sensações. Os principais sentimentos identificados foram o medo, dor e satisfação em ver o filho, como pode ser percebido nas seguintes falas:

"Também achei ruim porque tava sentindo muita dor, muita dor mermo, eu gritei não aguentei não (risos)" (A 03).

"No começo dói um pouco né? Eu me aperriei, fiquei desesperada... E foi assim uma experiência nova né?" (A 06).

"Bom... muita dor, realmente todo mundo sente" (A 07).

"Meu sentimento era só de medo, de morrer, de não conseguir... de não conseguir ter a menina" (A 08).

"Ah doeu (risos), doeu muito, mas só que eu pensava que ia doer mais ainda" (A 02).

A dor do processo parturitivo é passada de geração para geração como algo insuportável, pois durante toda a gravidez os familiares e amigos contam para a mulher o quanto $o$ trabalho de parto e parto é doloroso, o quanto a mulher sofre, ou seja, são repassados aspectos negativos desse momento da mulher, gerando assim medo e ansiedade, que podem intensificar a dor.

A dor que acompanha o parto é uma experiência subjetiva e complexa que varia de indivíduo para indivíduo. As características da dor relacionado ao trabalho de parto e parto podem envolver aspectos biológicos, culturais, socioeconômicos e de caráter emocional, assim as mulheres vivenciam esse momento de forma distinta, portanto é necessário que os profissionais respeitem a individualidade de cada paciente ${ }^{(14)}$.

A gestação e o parto são momentos de crise para as adolescentes, o que foi notório nas falas citadas anteriormente, isso se deve ao medo do desconhecido e de ser incapaz de parir, essa situação afloram os sentimentos como dúvida e ansiedade de algo que vivia no imaginário e que se tornará real. Desde muito jovens as mulheres esperam um parto permeado de dor, que posteriormente, o alívio venha junto ao prazer da chegada do filho ${ }^{(15)}$. A vontade e a recompensa de ver o filho eram maiores e foi o que tornou a dor suportável. É o que se percebe abaixo:

"Foi bom, gostei, porque o que eu queria mesmo era tirar minha filha, ter logo" (A 03).

"A dor vinha vindo, mais valeu apena, ter um bebezinho. Agradecer à Deus de ter me dado um filho, foi bom" (A 04).

"Eu tava achando bom, por que eu já sabia que era ele que já tava vindo" (A 05).

"Em compensação, apesar da dor, eu pensava muito nele, o bebê, apesar de toda a dor eu só queria que ele nascesse bem, com saúde, graças a Deus ele veio" (A 07).

"A minha vontade era de ver ele, dele nascer logo, na hora do parto também foi o mesmo" (A 09).

O sentimento observado durante as entrevistas era de ansiedade em relação ao nascimento da criança, da recompensa e satisfação das adolescentes por terem conseguido parir, apesar de toda a dor sentida durante o processo parturitivo, embora essa seja apreendida de forma negativa e dolorosa, há o lado de positividade, felicidade e simbolização da maternidade.

Durante a observação das expressões não verbais foi notório a face de felicidade expressada durante a fala das adolescentes de terem conseguido dar à luz, mesmo com toda a dor, medo e anseios sentidos durante o trabalho de parto e parto. Isso pode ser atribuído ao aflorar da maternidade que se concretiza com o nascimento do filho, com o primeiro contato visual e físico da mãe com o filho que vivia no imaginário e que se tornou real.

Para a humanização do parto, além da assistência qualificada dos profissionais, é fundamental a presença do acompanhante para controle da dor e desfecho favorável do parto. 0 direito ao acompanhante de escolha da mulher durante o trabalho de parto, parto e pós-parto, é garantido pela Lei $\mathrm{N}^{\circ} 11.108 / 2005^{(16)}$. A presença de uma pessoa de escolha da mulher é essencial, pois o apoio contínuo propicia benefícios físicos e emocionais, tornando a parturiente mais segura e autônoma, contribuindo para uma boa evolução do trabalho de parto e parto, favorecendo a 
vivência positiva desse momento ${ }^{(17)}$. A presença do acompanhante pode ser observada nas falas a seguir de duas adolescentes, as demais não citaram se tiveram ou não o acompanhante:

"Tive acompanhante direto" (A 01).

"Assim... na hora do parto mesmo quem tava ajudando era minha irmã, que eu pegava na mão dela, colocava força e tudo e foi a minha irmã" (A 10).

Além do acompanhante outro aspecto essencial para a manutenção do bem-estar materno e fetal é a oferta de alimentos e líquidos durante o processo parturitivo, pois a fome e a sede provocam desconforto e o trabalho de parto e parto consomem enormes quantidades de energia, e como não é possível prever sua duração, as fontes de energia, sobretudo a ingestão hídrica e de alimentos devem ser estimulados ${ }^{(18)}$. A alimentação durante o trabalho de parto foi um aspecto positivo relatado por somente uma das entrevistadas, enquanto as demais não se referiram se ingeriram ou não alimentos ou líquidos, como se observa a seguir:

"Tive alimentação, me deram água" (A 01).

Diante do que foi exposto, é possível perceber o quanto as tecnologias do cuidado como a oferta de alimentos e líquidos, presença do acompanhante entre outros são essenciais para o bem-estar materno e fetal, além de contribuir para o processo natural do trabalho de parto e parto, sem a necessidade de intervenções desnecessárias.

\section{A assistência do enfermeiro obstetra segundo o olhar das parturientes assistidas}

A atuação do enfermeiro obstetra no processo parturitivo contribui para a melhoria assistencial com o desenvolvimento de pesquisas que contribuem para a mudança da prática obstétrica, assim como o modelo assistencial, objetivando $\mathrm{o}$ atendimento seguro $\mathrm{e}$ humanizado ${ }^{(19)}$. O enfermeiro obstetra tem sua atuação regulamentada pela Lei Federal $\mathrm{N}^{\circ}$ 7.498/1986 e Decreto $\mathrm{N}^{\circ}$ 94.406/1987 que regulamenta esta última(20,21), e a resolução № 478/ 2015 que normatiza a atuação dos enfermeiros obstetras e obstetrizes e delimita suas responsabilidades no âmbito dos centros de parto normal e/ou casas de parto ${ }^{(22)}$. O enfermeiro obstetra está apto a realizar o parto normal sem distocia, aplicando as práticas baseadas em evidências científicas como preconiza a Organização Mundial da Saúde $(\mathrm{OMS})^{(23,24)}$.
Primeiramente, observou-se a percepção das puérperas sobre 0 atendimento dos enfermeiros obstetras e a importância da assistência desses profissionais para o processo do trabalho de parto e parto, conforme os depoimentos a seguir:

"Foi feito o possível, foi feito tudo, o que tinha que acontecer com as outras aconteceu comigo também, foi atendida, gostei" (A 04).

"Foi uma pessoa muito acalentosa, ele me ajudou bastante e na hora do parto foi calmo né? Que geralmente, esses enfermeiros eles são... e ele me ajudou bastante no meu parto" (A 06).

"Eu gostei muito da enfermeira que cuidou de mim, ela me deu muita assistência, tava comigo lá o tempo todo, sempre que eu pedi pra chamar ela tava lá, e eu gostei muito da assistência" (A 07).

"Enfermeira ajudou bastante, ela foi muito amiga também, se não fosse por ela, ia demorar mais ainda" (A 09).

"Achei bom, eles me trataram bem, até eu ter o neném direitinho, fizeram o parto direito, não me maltrataram" (A 01).

"E foi bom, a equipe também foi toda boa, todo tempo no meu pé, tava todo mundo junto comigo, tanto no trabalho de parto como no parto, foi muito bom, gostei da equipe. Tão de parabéns!" (A 10).

Diante dos relatos, é perceptível que as depoentes demonstraram satisfação com atendimento, evidenciando que a assistência foi humanizada, pois houve uma aproximação entre o enfermeiro e a adolescente, quebrando o paradigma da assistência tradicional, onde as mulheres permaneciam sozinhas durante todo o processo de parturição e o contato do profissional com as mesmas eram restritos aos procedimentos técnicos.

É dever dos profissionais de saúde receber com dignidade a mulher, seus familiares e recémnascidos. Para isso são necessárias atitudes éticas e solidárias e a organização da instituição de modo a criar um ambiente acolhedor ${ }^{(12)}$. Gestos de carinho e atenção são valorizados pelas adolescentes, e isso se deve ao momento de fragilidade e vulnerabilidade em que se encontram durante o processo parturitivo, é o que se percebe nos depoimentos a seguir:

"Seguraram na minha mão, conversavam comigo direto..."(A 01).

"Ele teve paciência comigo sendo que eu não tava tendo força e ele me ajudou a... me explicando direitinho"(A 02). 
"Segurou minha mão, foi ela que pegou o neném, sempre teve, até quando eu vim pra cá ela tava lá pertinho de mim"(A 07).

"Ela foi muito compreensiva, me ajudou bastante" (A 09).

O toque, como o simples segurar de mão, um olhar atencioso, causa uma sensação de segurança e bem-estar nas adolescentes, pois são gestos que passam confiança e estreitam a relação entre profissional e paciente, facilitando a assistência. Também é possível perceber a valorização que as adolescentes demonstraram da paciência dos enfermeiros obstetras assim como a presença constante dos mesmos.

Entre outros aspectos que facilitam à assistência está a estrutura física, e o centro obstétrico da maternidade onde foi realizado o estudo não possui uma estrutura física totalmente adequada para acolher as parturientes, mas o ambiente vem sofrendo transformações para que as pacientes possam ter privacidade e um espaço mais acolhedor. Uma das mudanças realizadas foi a implementação das divisórias entre os leitos nas salas de pré-parto, permitindo assim maior privacidade. Há também a presença de materiais que são utilizados durante o trabalho de parto e parto como a bola suíça, cavalinho e banqueta.

No transcorrer do processo de parturição a deambulação tem um papel extremamente importante, pois além de ser benéfica retiram o foco da atenção da mulher durante a expressão da dor. Essa prática favorece a contração uterina e aumentam o fluxo sanguíneo que chega ao feto, além disso, a posição ereta da parturiente favorece a ação da gravidade, auxiliando na progressão do trabalho de parto $^{(18)}$. Os efeitos da deambulação reduz o uso de ocitocina e de analgesia, além da menor frequência de parto vaginal instrumental como fórceps, extração a vácuo, episiotomia, entre outros $^{(25)}$.

Entre os métodos não farmacológicos de alívio da dor citados pelas depoentes além da deambulação, foram o uso do cavalinho, da bola suíça, banho de aspersão, massagens e posição de quatro apoios como se verifica a seguir:

"Para aliviar a dor eles caminharam comigo, mandaram eu ficar na bola, no cavalinho, ficar de quatro na cama em cima da bola, deram massagem nas minhas costas" (A 01).

"Me botou pra ficar na naquela bola, no cavalinho, um bocado de coisa assim pra ter logo" (A 03).
"Fizeram exercício, pra caminhar, ficar na bola, no cavalinho, baixar, se acocar" (A 04).

"Ela me colocou pra fazer o exercício na bola, no cavalinho, fez massagem" (A 07).

"Fiz exercício da bola, cavalinho, ficar de quatro na cama e pra andar..."(A 09).

"Fizeram massagem nas minhas costas, tavam me abanando, só..." (A 10).

"Fiz exercício com a bola, caminhei, banhei também" (A 08).

Nos relatos, percebe-se que algumas puérperas referiram que realizaram os exercícios como protagonistas do seu trabalho de parto, no entanto, outras verbalizaram a realização dos exercícios como algo imposto pelo enfermeiro obstetra que estava prestando assistência, demonstrando assim diferença de condutas e que alguns profissionais por vezes não respeitam o desejo da mulher.

Nos relatos, somente uma das adolescentes afirmou que os exercícios aliviaram a dor, as demais não comentaram se houve ou não amenização da dor, diferentemente do que ficou evidenciado na pesquisa. Em um estudo realizado em São Paulo, as mulheres relataram que os exercícios na bola de parto e o banho de aspersão e imersão aceleraram o parto e aliviaram a dor, sendo fonte de satisfação. Isso ocorre pelo efeito relaxante da água ${ }^{(26)}$.

$\mathrm{Na}$ maternidade onde ocorreu a pesquisa, o banho de imersão ainda não é realizado, pois a estrutura física do local não suporta a instalação de banheiras, no entanto, o banho morno de aspersão é oferecido, pois a água aquecida é uma estimulação cutânea de calor superficial que realizado a uma temperatura média de 3700 , está associado com o alívio da dor e ansiedade durante o trabalho de parto com redução do estresse, melhora no padrão das contrações e consequente correção da distorcia uterina ${ }^{(27)}$.

A massagem relatada pelas depoentes tem o potencial de promover o alívio da dor, proporciona contato físico com a parturiente, potencializa o efeito de relaxamento, melhora o fluxo sanguíneo e a oxigenação dos tecidos, e diminui o estresse emocional. A massagem é geralmente aplicada na região lombar durante as contrações uterinas ou onde a parturiente preferir $^{(28,29)}$.

O uso da bola suíça foi relatado pela maioria das entrevistadas, a mesma é usada para facilitar a adoção de postura vertical pela parturiente de forma confortável, trabalha os músculos do assoalho pélvico, além de ser uma 
alternativa de liberdade dos movimentos, tendo como resultado a participação ativa da mulher no processo parturitivo, facilitando a descida e rotação da apresentação fetal e estimulam as contrações uterinas ${ }^{(27)}$.

Os exercícios aceleram o trabalho de parto, isso se deve ao fato da mulher passar a exercer controle do seu corpo, tornando-se a protagonista do processo, além disso, os exercícios favorecem a posição verticalizada, facilitando o processo de dilatação, pois melhoram o fluxo sanguíneo fetal, aumentam a intensidade e eficácia das contrações, reduzem a dor e facilitam a ação da gravidade ${ }^{(30)}$. Isso foi percebido por algumas adolescentes como segue nos relatos a seguir:

"Eu achei bom que foi ligeiro, depois que eu fiz os exercícios, rápido eu tive ele" (A 04).

"Antes deu ter o neném, eu fiz bastante exercício, com a bola, ela colocou a bola pra mim ficar em cima, ficar de quatro, ai ela fez massagem nas minhas costas, e tudo aquilo ajudou né? Contribuiu pra que o parto fosse tão rápido quanto foi" (A 06).

"Me incentivaram a fazer exercício...mas ai eu que não queria né? Mas depois que realmente eu comecei a fazer exercício foi até mais rápido[...]" (A 08).

Mesmo com todos os benefícios da movimentação corporal que é conseguida com a realização dos exercícios durante o trabalho de parto, algumas parturientes não cooperam ou não se sentem à vontade para realizarem tais exercícios, seja por causa da dor ou por outros motivos e é necessário que a vontade da mulher seja respeitada. O que se observa nas falas a seguir é que os exercícios foram oferecidos, porém as parturientes não o fizeram:

"Eles ficaram dizendo as coisas que eram pra mim fazer[...] Não fiz exercício porque a dor tava muito forte, eles ofereceram, mais eu não quis não, por que eu não aguentei" (A 05).

"Não fiz exercício porque eu não aguentava, foi porque eu não quis mesmo, mas elas insistiram muito" (A 10).

Para as mulheres, a humanização também envolve receber informação, pois essa é uma das formas de transmitir tranquilidade e confiança ${ }^{(19)}$. A informação representa o cuidado na atenção, pois a sua ausência destitui da mulher o poder sobre seu corpo, impedido sua autonomia e participação ativa no processo de parir ${ }^{(15)}$. Nas falas a seguir, as depoentes relataram avaliação materno-fetal e orientação dos profissionais:
"Eles vinham me dar toque na hora certa e ouvir o coração do bebê na hora certa, porque tinha os minutos... Eles não ficavam direto dando toque e nem machucava" (A 01).

"Ele me ajudou me explicando direitinho" (A 02).

"Elas mesmo só tavam vendo as... como se chama... a dor na hora de vir né? Como é que tava, se era de quantos em quantos minutos" (A 10).

Além dos métodos não farmacológicos de alivio da dor para a humanização do parto, outros aspectos são importantes, como as informações da evolução do trabalho de parto e parto para a mulher e avaliação materno-fetal constante, que são percebidas como forma de atenção e respeito dos profissionais para com a parturiente. Além de aproximar a mulher e o profissional de saúde, proporcionado segurança para a parturiente, facilitando a adesão da sua participação ativa no trabalho de parto e parto. A maioria das adolescentes realizou exercícios e as que não o fizeram foi por outros motivos e não por falta de informação e incentivo.

O presente estudo apresentou algumas limitações como a dificuldade de entrevistar adolescentes que estão no puerpério, por ser um período delicado, de transição entre a infância e a fase adulta e do novo papel social que é o de ser mãe, com isso as entrevistas foram curtas, em alguns momentos com respostas monossilábicas, dificultando assim a interpretação dos resultados e o alcance do objetivo da pesquisa. Além disso, no cenário de coleta destaca-se que, mesmo as adolescentes sendo assistidas por equipe multiprofissional as depoentes reconheceram a importância da assistência do enfermeiro obstetra, o que reflete que cabe ao enfermeiro fazer-se conhecer, destacando seu trabalho junto a equipe multiprofissional e também de forma individual.

\section{CONSIDERAÇÕES FINAIS}

O estudo buscou compreender os sentimentos e sensações aflorados durante o processo parturitivo das adolescentes, assim como a percepção das mesmas da assistência recebida dos enfermeiros obstetras. Em relação aos sentimentos e sensações, os mais citados foram a dor, que é inclusive um aspecto do trabalho de parto passado de mãe para a filha, e a satisfação e recompensa de terem conseguido parir ao ver o filho e assim surgir o aflorar da maternidade. 
Entre os aspectos levantados pela maioria das puérperas adolescentes foram importantes a presença do acompanhante, o respeito e atenção passada pelos profissionais ao darem informações da evolução do trabalho de parto e ao demonstrar compreensão desse momento rodeado de dúvidas e anseios. O estímulo e informações sobre $o$ uso de tecnologias não invasivas de alívio da dor e o reconhecimento dos seus benefícios para a redução do tempo do trabalho de parto. Desta forma o cenário em questão potencializa estes aspectos pois, trata-se de campo de formação de enfermeiros obstetras.

Os profissionais de saúde devem prestar uma assistência humanizada de forma qualificada pautada nas boas práticas de atenção ao parto, para tal é necessária à sensibilização constante por meio de capacitação e treinamento dos profissionais, e para isso é necessário que todos que prestam assistência às parturientes trabalhem em conjunto, como uma equipe.

Portanto o reconhecimento das necessidades das adolescentes durante 0 processo parturitivo deve ser prioridade, para que assim, os profissionais de saúde possam prestar um atendimento de qualidade de acordo com as necessidades das mesmas.

\section{REFERENCES}

1 - Ribeiro VCS, Nogueira DL, Assunção RS, Silva RMR, Quadros KAN. Papel do enfermeiro da estratégia de saúde da família na prevenção da gravidez na adolescência. R. Enferm Cen Min. 2016;6(1):1957-75.

https://doi.org/10.19175/recom.v0i0.881

2 - Ministério da Saúde (BR). Marco legal: saúde, um direito de adolescentes. Brasília, DF: Ministério da Saúde; 2007 [citado em 18 dez 2016]. Disponível em: http://bvsms.saude.gov.br/bvs/publicacoes/07 0 $400 \mathrm{~m} . \mathrm{pdf}$

3 - Luz NF, Assis TR, Rezende FR. Puérperas adolescentes:percepções relacionadas ao prénatal e ao parto. ABCS Health Sci. 2015;40(2):804. https://doi.org/10.7322/abcshs.v40i2.735

4 - Leister N, Riesco MLG. Childbirth care:the oral history of women who gave birth from the 1940s to 1980s. Texto Contexto - Enferm. 2013;22(1):166-74.

https://doi.org/10.1590/S0104-

07072013000100020

5 - Camacho KG, Progianti JM. A transformação da prática obstétrica das enfermeiras na assistência ao parto humanizado. Rev Eletr Enf.
2013;15(3):648-55.

https://doi.org/10.5216/ree.v15i3.18588

6 - Lima AEF, Silva LJ, Maia ML, Pereira ALF, Zveiter M, Silva TMA. Assistência ao parto após a implementação do Programa Cegonha Carioca :a perspectiva da enfermagem. Rev Rene. 2015;16(5):631-8.

https://doi.org/10.15253/21756783.2015000500003

7 - Ministério da Saúde (BR). Programa Humanização do parto: humanização no pré-natal e nascimento. Brasília, DF: Ministério da Saúde; 2002 [citado em 18 ago 2016]. Disponível em: http://bvsms.saude.gov.br/bvs/publicacoes/parto .pdf

8 - Ministério da Saúde (BR), Secretaria de Atenção à Saúde. Manual prático para implementação da Rede Cegonha. Brasília, DF: Ministério da Saúde, 2011.

9 - Ministério da Saúde (BR). Resolução no 466, de 12 de dezembro de 2012. Aprova as seguintes diretrizes e normas regulamentadoras de pesquisa com seres humanos. Brasília, DF: Editora do Ministério da Saúde, 2012 [citado em 10 dez 2016]. Disponível em: http://bvsms.saude.gov.br/bvs/saudelegis/cns/20 13/res0466 1212 2012.html

10 - Ministério da Saúde (BR). Gestação de alto risco: manual técnico. $5 a$ ed. Brasília, DF: Ministério da Saúde; 2012 [citado em 20 DEZ 2016]. Disponível em: http://bvsms.saude.gov.br/bvs/publicacoes/man ual tecnico gestacao alto risco.pdf

11 - Gerhardt TE, Silveira DT. (Org). Métodos de pesquisa. Porto Alegre: Editora da UFRGS; 2009 [citado em 10 nov 2016]. Disponível em: http://www.lti.pro.br/userfiles/downloads/13 Li vro Metodos de Pesquisa.pdf

12 - Vargas PB, Vieira BDGV, Alves VH, Rodrigues $D P$, Leão DCMR, Silva LA. A assistência humanizada no trabalho de parto:percepção das adolescentes.Rev Pesq Cuid Fundam. 2013 [citado em 20 dez 2016];6(3):1021-35. Disponível em: http://www.seer.unirio.br/index.php/cuidadofun damental/article/view/3143/pdf 1351

13 - Rodrigues RF. A poética como pensamento da sensação. Cognitio-Estudos: Rev Eletr Filosofia. 2007 [citado em 5 jan 2017];4(2):160-4. Disponível em: https://revistas.pucsp.br/index.php/cognitio/artic le/viewFile/5760/4063

14 - Mafetoni RR, Shimo AKK. Métodos não farmacológicos para alívio da dor no trabalho de parto:revisão integrativa. Rev Min Enferm. 
2014;18(2):505-12.

https://doi.org/10.5935/1415-2762.20140037 15 - Scarton J, Prates LA, Wilhelm LA, Silva SC, Possati $A B$, llha CB. et al. "No final compensa ver o rostinho dele": vivências de mulheres primíparas no parto normal. Rev Gaúcha Enferm. 2015;36

https://doi.org/10.1590/1983-

\subsection{5.esp.56786}

16 - Brasil. Lei № 11.108, de 7 de abril de 2005. Altera a Lei $n=8.080$, de 19 de setembro de 1990, para garantir às parturientes o direito à presença de acompanhante durante o trabalho de parto, parto e pós-parto imediato, no âmbito do Sistema Único de Saúde - SUS. Diário Oficial União. 8 abr 2005.

17 - Santos ALS, Oliveira ARS, Amorim T, Silva UL. O acompanhante no trabalho de parto sob a perspectiva da puérpera. Rev Enferm UFSM. 2015;5(3):531-40.

https://doi.org/10.5902/2179769217337

18 - Takemoto AY, Corso MR. Parto humanizado e a assistência de enfermagem:uma revisão da literatura. Arq Ciênc Saúde UNIPAR. 2013;17(2):117-27.

https://doi.org/10.25110/arqsaude.v17i2.2013.5 $\underline{002}$

19 - Apolinário D, Rabelo M, Wolff LDG, Souza SRRK, Leal GCG. Práticas na atenção ao parto e nascimento sob a perspectiva das puérperas. Rev Rene. 2016;17(1):20-8. https://doi.org/10.15253/rev\%20rene.v17i1.2601 20 - Conselho Federal de Enfermagem - Cofen. Decreto no 94.406/87. Regulamenta a Lei no 7.498 , de 25 de junho de 1986, que dispõe sobre o exercício da Enfermagem, e dá outras providências. Diário Oficial União. 9 jun 1987; Seção 1:8853-5.

21 - Brasil. Lei № 7.498, de 25 de junho de 1986. Dispõe sobre a regulamentação do exercício da enfermagem e dá outras providências. Diário Oficial União. 26 jun 1986.

22 - Conselho Federal de Enfermagem - Cofen. Resolução no 478, de 14 de abril de 2015. Normatiza a atuação e a responsabilidade do Enfermeiro, Enfermeiro Obstetra e Obstetriz na assistência às gestantes, parturientes, puérperas e recém-nascidos nos Serviços de Obstetrícia, Centros de Parto Normal e/ou Casas de Parto e outros locais onde ocorra essa assistência; estabelece critérios para registro de títulos de Enfermeiro Obstetra e Obstetriz no âmbito do Sistema Cofen/Conselhos Regionais de
Enfermagem, e dá outras providências. Diário Oficial União. 27 jun 2016.

23 - Caus ECM, Santos EKA, Nassif AA, Monticelli M. O processo de parir assistido pela enfermeira obstétrica. Esc Anna Nery. 2012;16(1):34-40. https://doi.org/10.1590/S141481452012000100005

24 - Organização Mundial da Saúde - OMS. Maternidade segura: assistência ao parto normal: um guia prático. Brasília, DF: Ministério da Saúde; 1996.

25 - Mamede FV, Mamede MV, Dotto LMG. Reflexões sobre deambulação e posição materna no trabalho de parto e parto. Esc Anna Nery. 2007;11(2):331-6.

https://doi.org/10.1590/S141481452007000200023

26 - Jamas MT, Hoga LAK, Reberte LM. Narrativas de mulheres sobre a assistência recebida em um centro de parto normal. Cad Saúde Pública. 2013;29(12):2436-46.

https://doi.org/10.1590/0102-311X00039713

27 - Barbieri M, Henrique AJ, Chors FM, Maia NL, Gabrielloni MC. Banho quente de aspersão, exercícios perineais com bola suíça e dor no trabalho de parto. Acta Paul Enferm. 2013;26(5):478-84.

https://doi.org/10.1590/S0103-

21002013000500012

28 - Gallo RBS, Santana LS, Marcolin AC, Ferreira CHJ, Duarte G, Quintana SM. Recursos não farmacológicos no trabalho de parto:protocolo assistencial. Femina. 2011 [citado em 5 jan 2016];39(1):41-8. Disponível em: http://files.bvs.br/upload/S/0100-

7254/2011/v39n1/a2404.pdf

29 - Silva RC, Soares MC, Jardim VMR, Kerber NPC, Meincke SMK. O discurso e a prática do parto humanizado de adolescentes. Texto Contexto Enferm. 2013;22(3):629-36.

https://doi.org/10.1590/S0104-

$\underline{07072013000300008}$

30 - Macedo PO, Quitete JB, Lima EC, Santos I, Vargens OMC. As tecnologias de cuidado de enfermagem Obstétrica fundamentadas pela teoria ambientalista de Florence Nightingale. Esc Anna Nery. 2008;12(2):341-7. https://doi.org/10.1590/S1414$\underline{81452008000200022}$

Nota: Pesquisa financiada pelos autores. A pesquisa faz parte do Trabalho de Conclusão de Curso apresentado ao Programa de Residência em Área Profissional de Saúde Enfermagem Obstétrica. 
Recebido em: 23/02/2017

Aprovado em: 04/10/2017

Endereço de correspondência:

Priscilla Cavalcante Lima

Rua Vladimir do Rego Abreu, $n^{\circ} 1037$

CEP: 64019.762 Teresina/PI - Brasil

E- mail: priclima90@gmail.com 